\title{
DELIMITAÇÃO E ENCADEAMENTOS DE SISTEMAS AGROINDUSTRIAIS: O CASO DO COMPLEXO LÁCTEO DO RIO GRANDE DO SUL*
}

\author{
Marco Antonio Montoya ${ }^{\S}$ \\ Eduardo Belisário Finamore ${ }^{\alpha}$
}

\begin{abstract}
RESUMO
O artigo tem como objetivo identificar e delimitar agrupamentos produtivos que configuram o complexo lácteo gaúcho. Para isso, o processo metodológico utiliza-se da matriz insumo-produto do RS. O conjunto de informações gerado permitiu visualizar o fluxo de insumos e bens finais por origem e destino, bem como a dimensão econômica e encadeamentos que tem o complexo lácteo. Verificou-se que a produção do agrupamento formado pelos setores de leite natural e de leite beneficiado e outros laticínios apresenta um nível elevado de autonomia no suprimento de insumos tanto para as vendas $(99,54 \%)$ quanto para as compras $(77,92 \%)$. Verificou-se também que o complexo lácteo é um exportador líquido para outros estados, apresenta encadeamentos significativos para frente e para trás e constitui-se como setor-chave para o RS. Trata-se, portanto, de um agrupamento produtivo em processo de expansão.
\end{abstract}

Palavras-chave: complexo agroindustrial lácteo, relações intersetoriais, insumo-produto.

\begin{abstract}
The article has as objective to identify and to define productive groupings that configure the milk's agribusiness of the Rio Grande do Sul (RS) economy. For that, the methodological process used was the matrix input-output of the RS. The group of information generated allowed to visualize the flow of input and final goods for origin and destiny, as well as the economic dimension and linkages of the milk's agribusiness. It was verified that the production of the grouping formed by the sections of natural milk and of milk beneficiary and other derived presents a high level of autonomy in the supply of input for the sales $(99,54 \%)$ as for the purchases $(77,92 \%)$. It was also verified that the milk's agribusiness is a liquid exporter for another states of Brasil, it presents significant forward and backward linkages and it is constituted as key section for RS. It is, therefore, of a productive grouping in expansion process.
\end{abstract}

Key words: agribusiness, intersectorial relationships, input-output.

JEL classification: D57, R15, C67.

* No Projeto, o aluno Paulo Roberto Scalco participa como bolsista do PIBIC/CNPq.

$\S$ Professor Titular da Faculdade de Ciências Econômicas, Administrativas e Contábeis da Universidade (FEAC) de Passo Fundo (UPF), RS. Pesquisador do Centro de Pesquisa e Extensão da FEAC e Doutor em Economia Aplicada pela Escola Superior de Agricultura Luiz de Queiroz (ESALQ) da Universidade de São Paulo. E-mail: montoya@upf.tche.br

a Professor Adjunto da Faculdade de Ciências Econômicas, Administrativas e Contábeis da Universidade (FEAC) de Passo Fundo (UPF), RS. Pesquisador do Centro de Pesquisa e Extensão da FEAC e Doutor em Economia Rural pela Universidade Federal de Viçosa. E-mail: finamore@upf.tche.br

Recebido em abril de 2004. Aceito em agosto de 2005. 


\section{INTRODUÇÃO}

Nos últimos anos, diversos estudos vêm analisando os sistemas agroindustriais por diferentes enfoques. Duas metodologias de maior destaque são a dos Sistemas dos Complexos Agroindustriais (CSA - Commodities System Aproach) e a análise de Cadeias de Produção (Filières). Nesses estudos foram introduzidos aspectos teóricos da Economia de Custos de Transação e Teoria de Contratos, presentes na Nova Economia das Instituições. Mais recentemente, complementando essas análises, desenvolveu-se um enfoque chamado de Gestão de Cadeias de Suprimentos (SCM Supply Chain Management). A diferença básica desses estudos é que o primeiro (CSA) está relacionado com as observações macro do sistema e as medidas de regulação dos mercados - geralmente implementados por órgãos governamentais -, ao passo que o último (SCM) analisa os mecanismos de coordenação do sistema implementados por seus próprios integrantes - empresas privadas e outras instituições. O que se observa é que esses diferentes enfoques se complementam e permitem analisar a estrutura e a competitividade dos sistemas agroindustriais.

Nesse contexto, por exemplo, Davis e Goldberg (1957), utilizando o enfoque macroeconômico, demonstram que as técnicas mais adequadas para se mensurar o agronegócio e a dinâmica agroindustrial do sistema econômico tomam como base as matrizes insumo-produto desenvolvidas por Leontief (1951), as quais, além de fornecerem informações sobre uma elevada gama de setores da economia, descrevem o sistema econômico em termos de circulação, no qual todas as vendas são igualmente compras, e todos os produtos, a só um tempo, são insumos à medida que sejam aproveitáveis por outra cadeia produtiva do sistema. Esse referencial teórico e empírico foi utilizado no Brasil por Araújo et al. (1990), Lauschner (1993), Furtuoso (1998), Montoya e Guilhoto (2000), Guilhoto et al. (2000), Montoya et al. (2001), Finamore (2001) e Montoya e Finamore (2001), cujos resultados salientam a importância do agronegócio como alicerce para o processo de desenvolvimento econômico do País, dadas as ligações intersetoriais fortes - para frente, para trás e para os lados - que apresenta sobre o resto da economia.

Complementando esses estudos, análises mais particularizadas podem ser implementadas usando matrizes insumo-produto, por meio da identificação e/ou delimitação de agrupamentos produtivos. A identificação de agrupamentos produtivos procura aglutinar atividades altamente inter-relacionadas em termos de transações intermediárias e que representam uma relativa independência com o restante das atividades de um sistema econômico, isto é, os agrupamentos reúnem atividades com alto grau de integração, de modo que os intercâmbios que ocorrem em seu interior tornam-se mais relevantes que os que se dão com o resto do sistema. Os agrupamentos ou complexos assim definidos tendem a permanecer no tempo, marcando uma característica estrutural da economia.

Neste sentido, o objetivo deste estudo é a identificação de agrupamentos produtivos que têm como base a exploração de recursos naturais abundantes, particularmente aqueles que se desenvolvem em torno da produção de leite natural. Espera-se, com isso, gerar informações sobre as particularidades do complexo lácteo do Estado do Rio Grande do Sul, permitindo visualizar, de forma integrada, as relações intersetoriais que existem entre os setores de produção de Leite natural com a Indústria láctea e com os demais setores produtivos da economia gaúcha como um todo.

Para tanto, o artigo apresenta, em seqüência, o referencial teórico e metodológico utilizado. Após, apresenta-se, com base nos resultados obtidos, uma descrição dos fluxos intersetoriais de insumos e produtos que delimitam e caracterizam o complexo lácteo gaúcho e, por último, expõemse as principais conclusões e considerações finais. 


\section{Metodologia}

A seguir são apresentados os processos de delimitação de agrupamentos produtivos, bem como os multiplicadores e os índices de encadeamentos intersetoriais a serem calculados.

\subsection{Delimitação e construção do agrupamento produtivo}

$\mathrm{Na}$ análise dos agrupamentos produtivos são discriminadas as compras e/ou vendas de matérias-primas diretas ou específicas - que são as que definem o caráter dos agrupamentos - e ainda as outras compras e/ou vendas de insumos ou serviços que, podendo ser importantes, apresentam vinculação relativamente uniforme com todos os setores da economia e, portanto, não se distinguem diretamente de nenhum agrupamento. Esse primeiro tipo de relação gera os encadeamentos para trás e para frente que integram as atividades dos agrupamentos produtivos; o segundo tipo dá lugar a encadeamentos para "os lados”, isto é, para atividades que não se integram verticalmente ao agrupamento produtivo.

Segundo Ramos (1998), dentro do esquema de um agrupamento produtivo típico, baseado, por exemplo, no processamento de recursos naturais, encontram-se encadeamentos para trás a partir de compras de insumos químicos, maquinário específico, serviços especializados e outros. Já encadeamentos para frente são encontrados a partir das vendas para outros setores produtivos, que serão tanto maiores quanto mais difundido for o produto utilizado como insumo das demais indústrias. Os encadeamentos para os lados são energia, comércio e serviços financeiros.

Para identificar esse conjunto de encadeamentos de um agrupamento, a metodologia empregada utiliza as informações estatísticas das relações intersetoriais contidas nas matrizes de insumoproduto.

O Quadro 1 mostra o esquema de apresentação dos dados, conhecido como matriz de transações. Nas linhas localizam-se as vendas dos setores e nas colunas as compras dos setores.

Observam-se três tipos de relações. A primeira relação ocorre entre as empresas cujo fluxo de transações intermediárias pode ser representado por uma matriz $X$, onde cada elemento, $x_{i j}$, representa o valor da produção do setor $i$ consumido no setor $j$. Dentro das transações intermediárias existe uma matriz $M$ de importações (interestaduais e internacionais) e uma matriz $I$ de impostos indiretos menos os subsídios. Uma segunda relação ocorre entre as empresas e as famílias, cuja produção destinada para a demanda final é dividida em quatro categorias: consumo das famílias, consumo do governo, investimentos líquidos e exportações. A terceira relação, também entre as empresas e as famílias, mostra como o valor adicionado pelos setores remunera os fatores de produção utilizados nos processos produtivos. Parte do valor adicionado a preços básicos é destinada à remuneração dos trabalhadores na forma de salários e contribuições previdenciárias, parte é destinada ao governo, na forma de impostos que incidem sobre a renda e a propriedade; por fim, parte do valor adicionado dos setores é destinada à remuneração do capital investido nas atividades produtivas na forma de excedente operacional bruto, uma proxy do lucro bruto. 


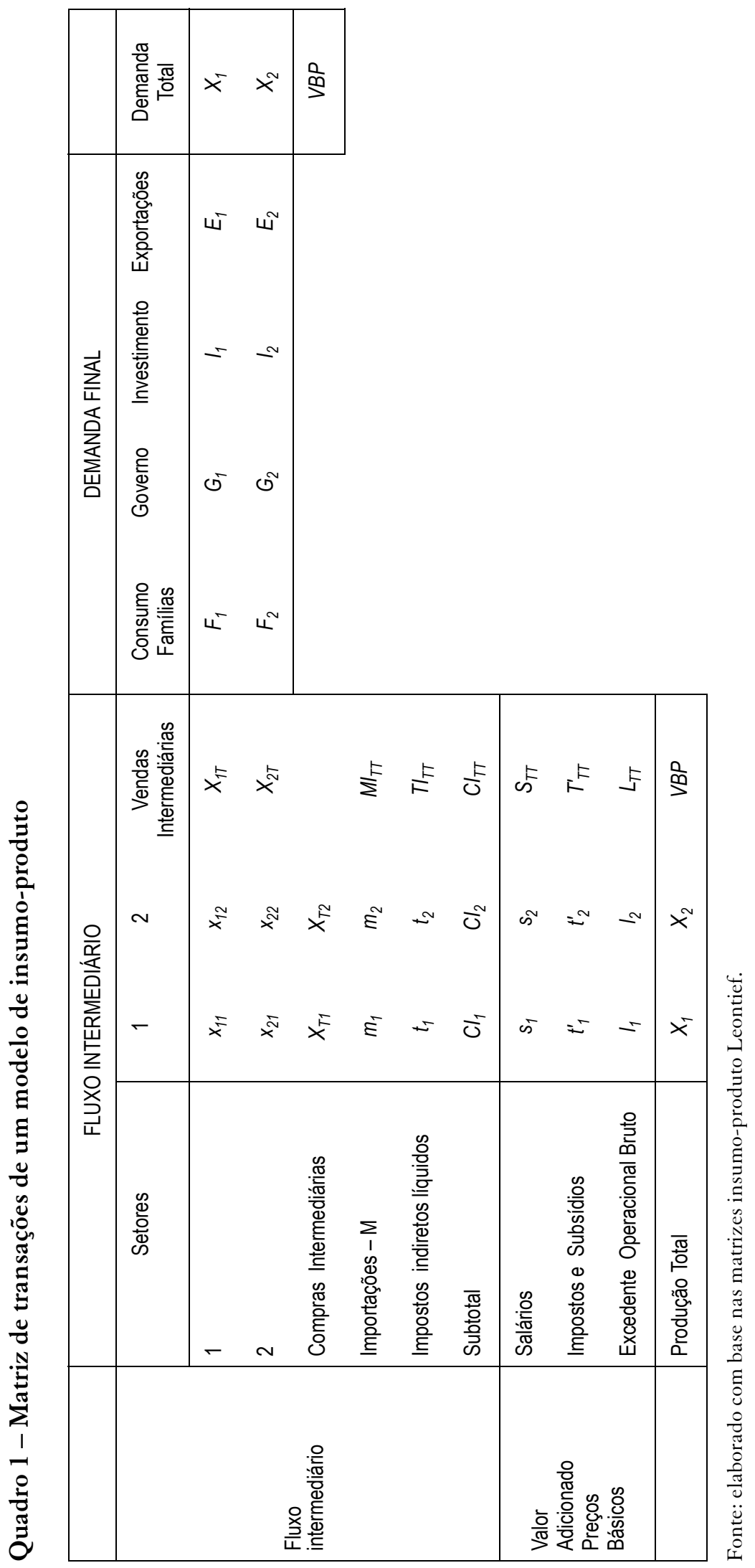


Para a correta identificação dos agrupamentos produtivos é necessário que os setores sejam agrupados com certo grau de homogeneidade nos produtos que os compõem, sendo sugerido trabalhar-se com matrizes de alto grau de desagregação. Para isso, a matriz de insumo-produto estadual foi compilada na forma de produto-produto com tecnologia baseada na indústria, resultando em uma matriz de dimensão 43 x 43 produtos. Cabe também salientar que na matriz compilada foram implementados ajustes de consistência por origem e destino.

\subsubsection{Grau de autonomia intersetorial}

O critério para verificar o grau de inter-relação existente dentro de um agrupamento produtivo é o coeficiente estatístico denominado "grau de autonomia" de cada agrupamento. Tal procedimento metodológico foi utilizado por Vaillant (1999) para delimitar o complexo produtivo lácteo do Uruguai.

Esse coeficiente mede a relação das compras intermediárias (vendas intermediárias) que se realizam dentro do agrupamento produtivo, como proporção das compras intermediárias totais (vendas intermediárias totais) do agrupamento produtivo.

$$
\begin{aligned}
& \text { Autonomia de vendas do setor } i=\sum_{j=1}^{k} x_{i j} / \sum_{j=1}^{n} x_{i j} \\
& \text { Autonomia de compras do setor } j=\sum_{i=1}^{k} x_{i j} / \sum_{i=1}^{n} x_{i j} \\
& \text { Autonomia global }=\sum_{i=1}^{k} \sum_{j=1}^{k} x_{i j} / \sum_{i=1}^{n} \sum_{j=1}^{n} x_{i j}
\end{aligned}
$$

em que: $k=$ setores que pertencem ao agrupamento

$$
n=\text { todos os setores }
$$

Quando são identificados agrupamentos produtivos com alto grau de autonomia em vendas, trata-se de um agrupamento organizado em torno das atividades vendedoras de insumos ou matérias-primas. Já quando a autonomia em compras é alta, o agrupamento produtivo está organizado em torno de uma atividade basicamente final.

O método empregado para escolher um agrupamento produtivo foi selecionar os conjuntos de setores de forma que os perfis linha (estrutura das vendas intermediárias por setor) e os perfis coluna (estrutura de compras intermediárias por setor) tenham um valor do parâmetro de autonomia do setor analisado (em vendas ou em compras) de $100 \%$. 


\subsection{Multiplicadores e encadeamentos intersetoriais}

A literatura clássica sobre os modelos insumo-produto chama a atenção para as condicionantes que derivam das relações intersetoriais e as possibilidades de expansão de uma atividade econômica em função do crescimento na demanda. Isso porque o efeito total de um setor no sistema econômico é o resultado dos encadeamentos para trás e para frente que possui.

Uma atividade com fortes encadeamentos para trás em relação aos encadeamentos totais denota que a atividade se encontra localizada na fase de produção de bens finais e atua, basicamente, como receptora de insumos dos outros setores; ao contrário, se tiver fortes efeitos para frente, tratase de um setor basicamente produtor de matéria-prima que fornece a outros setores do sistema insumos intermediários de forma direta ou indireta. A importância relativa dos encadeamentos para frente e para trás dá indícios do lugar que ocupa o setor na cadeia produtiva e permite classificá-lo como uma atividade provedora ou processadora de insumos.

Portanto, considerando a relevância de analisar as relações intersetoriais que vão além dos limites do complexo lácteo, torna-se necessário mensurar multiplicadores setoriais e o poder de encadeamento ou efeito dinamizador das atividades que formam o núcleo do complexo sobre o resto do sistema econômico. Com esse fim, foram mensurados o multiplicador de renda e as relações intersetoriais por meio do índice de Rasmussen (1956) e Hirschman (1958).

O multiplicador de renda tipo I é definido como a somatória da coluna típica da matriz inversa de Leontief $B$. Assim, quanto maior for este índice, maior será a capacidade do setor de gerar renda no sistema econômico a partir de efeitos diretos e indiretos.

Já com o índice de Hirschman-Rasmussen podem ser determinados os setores que teriam o maior poder de encadeamento dentro da economia, ou seja, os índices de ligações para trás, que estimam o quanto um setor demanda dos outros, e os índices de ligações para frente, que estabelecem o quanto este setor é demandado pelos outros. Desse modo, define-se $b_{i j}$ como sendo um elemento da matriz inversa de Leontief $B ; B^{*}$ como sendo a média de todos os elementos de $B$ e $B_{* j} ; B_{i *}$ como sendo, respectivamente, a soma de uma coluna e de uma linha típica de $B$. Têm-se, então, os índices.

Índices de ligações para trás (poder de dispersão):

$$
U_{j}=\left[B_{* j} / n\right] / B^{*}
$$

Índices de ligações para frente (sensibilidade da dispersão):

$$
U_{i}=\left[B_{i *} / n\right] / B^{*}
$$

Rasmussen e Hirschman estabeleceram que índices para frente ou para trás maiores do que um indicam setores acima da média, portanto, setores-chave com poder de encadeamento ou efeito dinamizador para o crescimento da economia.

\subsection{Fonte dos dados}

Os dados utilizados foram extraídos das tabelas de insumo-produto e das contas econômicas integradas do Rio Grande do Sul do ano de 1998, fornecidas pela Fundação de Economia e Estatística (FEE). As informações utilizadas são a preços básicos, e encontram-se em milhões de reais de 
1998. Para a compilação das matrizes, adotou-se o modelo produto-produto com tecnologia baseada na indústria. Em geral, as estatísticas do estado utilizadas representam as últimas informações disponíveis em matéria de insumo-produto; portanto, o presente estudo, baseado na fonte empregada, tem o grau máximo de atualização possível.

Finalmente, deve-se salientar que a análise insumo-produto considera os coeficientes técnicos fixos e assume que os preços são constantes. Apesar dessa limitação, a análise insumo-produto se constitui numa ferramenta poderosa, talvez a melhor disponível, quando se faz necessária a identificação das relações intersetoriais de um conjunto de atividades de uma região ou sistema econômico.

\section{AS RELAÇÕES INTERSETORIAIS DO COMPLEXO LÁCTEO GAÚCHO}

O conjunto de políticas nacionais, iniciadas no final da década de 1980 e aceleradas na de 1990, tinha como objetivos a desregulamentação do mercado, a estabilização da economia e a abertura comercial. Em decorrência disto, o complexo lácteo do Rio Grande do Sul passou, na década dos anos 1990, por mudanças estruturais profundas, uma vez que essas políticas nacionais promoveram, no setor, a liberalização e diferenciação dos preços da matéria-prima, as guerras de ofertas nas prateleiras dos supermercados, a entrada de produtos importados, as alianças estratégicas no meio empresarial, a ampliação do poder dos laticínios multinacionais e dos supermercados, a ampliação da coleta a granel, a redução global do numero de produtores, a reestruturação geográfica da produção etc.

As mudanças estruturais no complexo lácteo assinalam ganhos de produtividade na produção de leite natural devido ao maior grau de articulação com a indústria processadora. ${ }^{1}$ Não em poucos casos, os níveis de articulação chegam a uma integração vertical total, já que, por um lado, a indústria láctea se integra para trás, controlando e coordenando a produção de leite natural e, por outro, os produtores de leite avançam para frente e industrializam sua produção, ou ambos os processos simultaneamente.

A questão é: qual é o grau de articulação intersetorial que existe entre o setor leite natural e a indústria láctea? Até que ponto essas articulações intersetoriais se estenderam para outros setores provedores de insumos, bens de capital, serviços ou de indústrias agroalimentares que utilizem a produção de leite natural e da indústria láctea como insumos?

\subsection{O complexo lácteo do Rio Grande do Sul}

Para responder a essas questões, foram selecionados quatro conjuntos de setores em torno do setor lácteo, de acordo com os perfis linha (estrutura das vendas intermediárias por setor) e os perfis coluna (estrutura de compras intermediárias por setor) do setor de Leite Natural e do setor da Indústria de Lácteos (Leite Beneficiado e outros Laticínios), respectivamente. Escolheram-se os setores de modo a fazer com que o valor do parâmetro de autonomia do setor analisado (em vendas ou em compras) fosse de $100 \%$. No caso do perfil linha (vendas), as colunas foram ordenadas segundo a importância de cada setor da Matriz de Insumo-Produto como receptor das vendas do setor analisado; no caso do perfil coluna (compras), as linhas foram ordenadas de acordo com a importância de cada setor como provedor do setor analisado.

1 O crescimento e a eficiência da produção de leite do RS foram notórios: em 1991, o Estado produziu 1.488 milhões de litros e em 2002 subiu para 2.330 milhões de litros, fazendo com que o Estado contribuísse com 10,76\% da produção nacional; desde o ano de 1991 a 2002 a produtividade cresceu de 1.254 para 1.964 litros vaca/ano, ou seja, um aumento de 56,62 pontos porcentuais no período, o que fez com que o Estado apresentasse a maior produtividade nacional em 2002. 
A seguir são apresentados os quatro agrupamentos com suas principais relações, com o objetivo de apresentar, esquematicamente, a visão sistêmica do complexo leite gaúcho.

\section{Primeiro agrupamento}

O primeiro agrupamento, apresentado na Tabela 1 e na Figura 1, mostra as informações do perfil linha do setor de Leite Natural, formado pelos setores Leite natural (5) e Leite beneficiado e outros laticínios (24), classificados como setores centrais. Observa-se que a autonomia das vendas intermediárias é de $100 \%$, sendo 95,26\% das vendas intermediárias destinadas ao setor de Leite Beneficiado e Outros Laticínios (24) e 4,74\% destinadas a si próprio. Observa-se também, pela relação entre Vendas Intermediárias e Valor Bruto da Produção (VI/VBP), que 94,20\% do Leite Natural se destinam ao processamento da indústria Láctea e apenas 5,8\% das vendas desse setor são reservadas à demanda final, para o consumo das famílias, no Rio Grande do Sul. Esses fatos revelam que o setor Leite Natural (5) constitui-se no fornecedor de insumo direto, por excelência, da indústria Láctea (24).

Tabela 1 - Análise do perfil linha do setor 5 - Vendas intermediárias e grau de autonomia

\begin{tabular}{llccccc}
\hline $\mathrm{N}^{\mathrm{a}}$ & \multicolumn{1}{c}{ RS 1998 } & Vendas (R\$) & 24 & 5 & $\begin{array}{c}\text { AUTONOMIA } \\
\text { DE VENDAS }\end{array}$ & VI/VBP \\
\hline 5 & Leite natural & 401,30 & $95,26 \%$ & $4,74 \%$ & $100,00 \%$ & $94,20 \%$ \\
24 & Leite beneficiado e outros Laticínios & 160,87 & $98,39 \%$ & $0,00 \%$ & $98,39 \%$ & $12,03 \%$ \\
\hline & Total & & & & $99,54 \%$ & \\
\hline
\end{tabular}

Fonte: Elaborado com base no Anexo 1.

O setor 24 apresenta um alto grau de autonomia de vendas intermediárias nesse agrupamento, em que $98,39 \%$ são realizadas para si própria. Outros $1,61 \%$ de suas vendas destinadas ao consumo intermediário não são aqui identificados, ou seja, são vendidos a outros setores da economia gaúcha que não os setores 5 e 24. No entanto, a relação entre Vendas Intermediárias e Valor Bruto da Produção (VI/VBP) revela que somente 12,03\% (11,84\% é vendido para si mesmo e 0,20\% para outros setores não especificados) de suas vendas têm um uso intermediário, ou seja, trata-se de um setor voltado para o atendimento da demanda final

A autonomia global das vendas intermediárias desse agrupamento produtivo do complexo lácteo é muito alta $(99,54 \%)$, ou seja, do total de suas vendas intermediárias, apenas $0,46 \%$ tem como destino outros agrupamentos produtivos aqui não identificados.

\section{Figura 1 - Decomposição das vendas intermediárias}

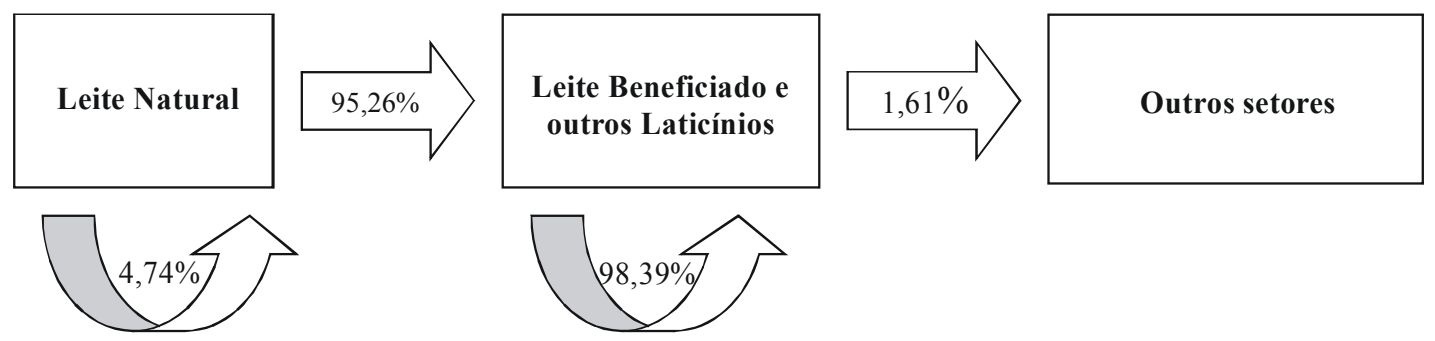

Fonte: Elaborado com base na Tabela 1. 
Quando se faz a análise das compras intermediárias (coluna) dos setores desse agrupamento (Tabela 2), observa-se que a autonomia em compras intermediárias do setor Leite Beneficiado e Outros Laticínios (24) é de 82,24\% - sendo 58,16\% adquiridos do setor 5 e 24,08\% do próprio setor -, ao passo que a do setor Leite natural (5) é de 31,25\% - adquiridos em sua totalidade de si mesmo. Isso indica que os setores 24 e 5 compram 17,76\% e 68,53\%, respectivamente, das matérias-primas estaduais utilizadas de outros setores não especificados nesse agrupamento. A autonomia global de compras intermediárias é de 77,92\%, ou seja, somente 22,08\% de suas compras intermediárias adquiridas dentro do Estado do Rio Grande do Sul são oriundas de outros setores que não fazem parte desse agrupamento produtivo.

Vale salientar que a estrutura das compras intermediárias totais (I) dos setores produtivos é composta por insumos estaduais, insumos importados de outros estados brasileiros e do mercado internacional, além da carga tributária. A partir dessa estrutura, pode-se obter o Valor Adicionado (VA) pelos setores subtraindo do Valor Bruto da Produção o total de insumos utilizados (I). (Ver Anexo 1 e Quadro 1).

Tabela 2 - Análise do perfil linha do setor 5 - Compras intermediárias e grau de autonomia

\begin{tabular}{llcccccc}
\hline $\mathrm{N}^{\mathrm{a}}$ & \multicolumn{1}{c}{$\mathrm{RS} 1998$} & Compras (R\$) & 5 & 24 & $\begin{array}{c}\text { AUTONOMIA } \\
\text { DE COMPRAS }\end{array}$ & I/NBP & VA/VBP \\
\hline 24 & Leite beneficiado e outros & 657,27 & $58,16 \%$ & $24,08 \%$ & $82,24 \%$ & $57,30 \%$ & $42,70 \%$ \\
5 & laticínios & 60,91 & $31,25 \%$ & $0,00 \%$ & $31,25 \%$ & $24,19 \%$ & $75,81 \%$ \\
\hline & Leite natural & & & $77,92 \%$ & & \\
\hline
\end{tabular}

Fonte: Elaborado com base no Anexo 1.

Nesse contexto, o setor 24 tem uma relação I/VBP de 57,30\%, o que indica que 42,70\% do valor da produção é acrescentado por esse setor à economia estadual. Já no caso do setor 5, a proporção do Valor Adicionado sobre o Valor Bruto da Produção alcança quase três quartos (75,81\%). Estes indicadores mostram que este é um setor com um produto menos elaborado, que adiciona, em termos relativos, mais valor $(75,81 \%)$ que o setor com um produto de maior grau de elaboração $(42,70 \%)$. Este aparente paradoxo pode ser explicado pelo total de ativos (estoques de capitais) utilizados pelos setores produtivos. O que se precisa saber, portanto, é qual a renda (fluxo) gerada por unidade de investimento (estoque) no setor de produção rural (Leite Natural) com relação à renda do setor a jusante (Indústria Láctea). As informações sobre os estoques de capital não são disponíveis para o Rio Grande do Sul. No entanto, segundo Lauschner (1995, p. 40-41), a produtividade do capital nas explorações rurais (em torno de $6,7 \%$ de renda sobre cada unidade de investimento) está em total contraste com a produtividade do capital a jusante e a montante do complexo rural (que está em torno de 120\%). Em outras palavras, o setor de Leite Natural, embora obtenha uma margem de contribuição elevada (75,93\%), tem também elevados custos de oportunidade do investimento com altos ativos em terra, maquinário, animais, e outras condições de produção. Tal fato é também verificado por Gomes (2002), uma vez que este observa custos variáveis baixos na produção leiteira nacional associada a um custo fixo médio elevado, devido à pequena escala de produção, o que pressiona a margem de lucro unitária do produtor, levando-o a obter baixos lucros totais.

Quando é analisada a distribuição dos custos de fabricação dos setores produtivos para esse agrupamento, verifica-se, com base no Anexo 1, que para o setor de Leite Beneficiado e outros Laticínios (24) 85,77\% de seus insumos são de origem estadual; 13,47\% de origem interestadual e so- 
mente $0,48 \%$ do mercado internacional, evidenciando, com isso, um elevado nível de autoabastecimento de insumos intermediários. Já o setor de leite natural (5) mostra que apenas 59,12\% do total de insumos têm origem estadual; 33,57\% origem interestadual e 6,65\% origem internacional. Esta análise da distribuição dos custos revela em quanto as ligações dos setores desse agrupamento produtivo ultrapassam as fronteiras do Estado do Rio Grande do Sul.

\section{Segundo agrupamento}

O segundo agrupamento analisado, com base no perfil linha do setor de Leite Beneficiado e outros Laticínios (24), incorpora, além dos setores centrais, os setores ligados à administração pública. Com a introdução dos setores públicos, a autonomia de vendas intermediárias do setor 24 passa para $100 \%$. As informações da Tabela 3 mostram que 98,39\% das vendas intermediárias são destinadas ao próprio setor - como identificado no agrupamento anterior - e o restante $(1,61 \%)$ aos setores de Administração (40), Saúde (41) e Educação (42) públicas. A autonomia de vendas global, nesse segundo agrupamento, é de $100 \%$, em virtude do fato de o setor público, por sua natureza, não destinar bens e serviços para a demanda intermediária.

Tabela 3 - Análise do perfil linha do setor 24 - Vendas intermediárias e grau de autonomia

\begin{tabular}{llrrr}
\hline $\mathrm{N}^{\mathrm{a}}$ & \multicolumn{1}{c}{ Setor } & Vendas (R\$) & Vendas (\%) & Autonomia \\
\hline 5 & Leite natural & 0 & $0,00 \%$ & $100 \%$ \\
24 & Leite beneficiado e outros laticínios & 158,28 & $98,39 \%$ & $100 \%$ \\
40 & Administração pública & 1,70 & $1,06 \%$ & $\mathrm{ND}$ \\
41 & Saúde pública & 0,28 & $0,18 \%$ & $\mathrm{ND}$ \\
42 & Educação pública & 0,59 & $0,37 \%$ & $\mathrm{ND}$ \\
\hline & Total & 160,86 & $100,00 \%$ & $100 \%$ \\
\hline
\end{tabular}

ND: o setor público não possui vendas intermediárias, portanto, não possui esse indicador.

Fonte: dados da pesquisa.

Figura 2 - Distribuição das vendas intermediárias e finais

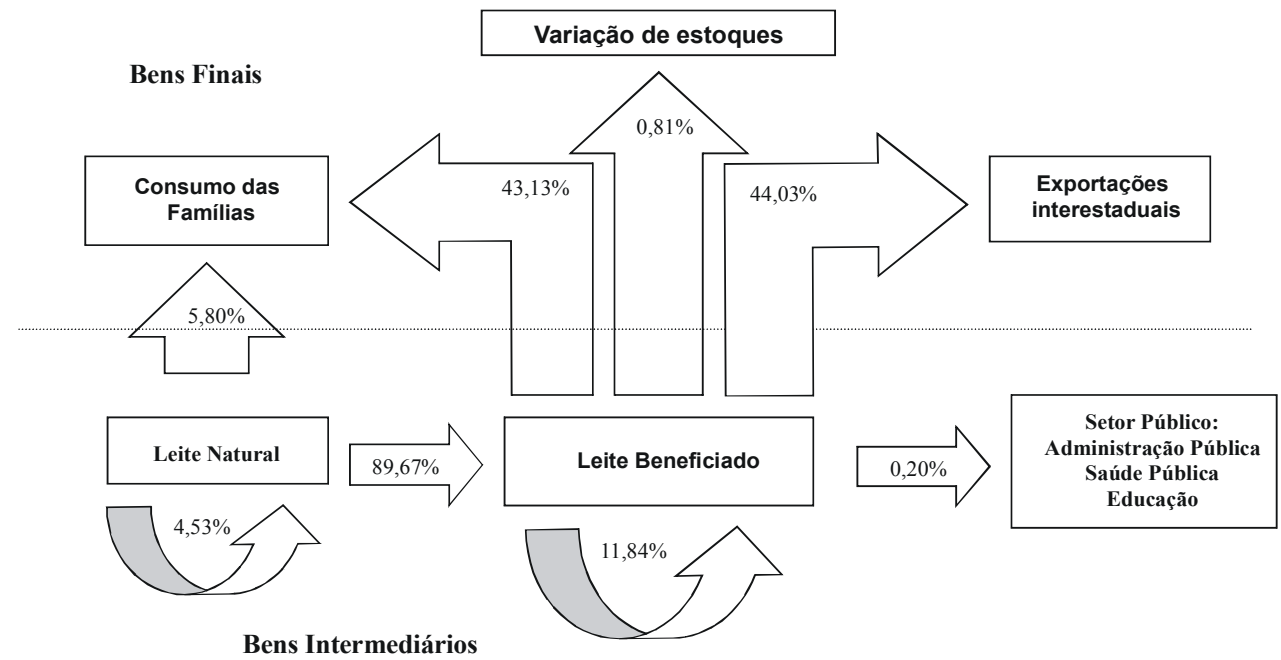

Fonte: elaborado com base nas Tabelas 1, 3 e Anexo 1. 


\section{Terceiro agrupamento}

A distribuição das vendas intermediárias e finais obtida a partir dos dois primeiros agrupamentos produtivos com autonomia de vendas de $100 \%$ pode ser visualizada, de forma integrada, na Figura 2. Fica evidente que o setor leite é um fornecedor de matérias-primas para a indústria Láctea, e em torno deste recurso desenvolve-se o setor de Leite Beneficiado e outros Laticínios, que destina mais de três quartos de sua produção para a demanda final, em cuja estrutura se observa que $43,13 \%$ é absorvida pelas famílias, $0,81 \%$ constitui variação de estoque e os restantes 44,03\% são destinados para outros estados brasileiros (ver Anexo 1). Este fato demonstra as vantagens comparativas e competitivas do complexo produtivo gaúcho. Devido à limitação de fonte de dados, não se pode observar se o destino das exportações gaúchas para outros estados se dirige para a demanda das famílias ou se para a demanda intermediária. Mais estudos deverão ser elaborados para investigar as ligações com cadeias produtivas de outros estados brasileiros.

$\mathrm{Na}$ Tabela 4 apresenta-se a composição por setores, em reais e em porcentagem, das compras de insumos estaduais realizadas pelo setor 5 (Leite Natural).

Esse agrupamento é formado de modo a fazer com que o grau de autonomia das compras intermediárias do setor Leite Natural (5) seja de 100\%. Com este procedimento verifica-se que o primeiro agrupamento apresentado foi expandido, e além dos 31,25\% das compras intermediárias fornecidas pelo próprio setor, existem ainda 68,75\% de compras de outros insumos diretos (demais produtos alimentares) e difundidos (todos os outros insumos).

Tabela 4 - Análise do perfil coluna do setor 5 - Compras de insumos estaduais e grau de autonomia em compras

\begin{tabular}{|c|c|c|c|c|}
\hline $\mathrm{N}$ & SETOR & COMPRAS (R\$) & COMPRAS (\%) & AUTONOMIA \\
\hline 5 & Leite natural & 19,03 & $31,25 \%$ & $100,00 \%$ \\
\hline 13 & Papel, celulose, papelão e artefatos & 0,07 & $0,12 \%$ & $97,84 \%$ \\
\hline 15 & Demais produtos químicos & 3,31 & $5,44 \%$ & $24,40 \%$ \\
\hline 17 & Combustiveis e demais produtos do refino & 4,90 & $8,04 \%$ & $36,65 \%$ \\
\hline 26 & Demais produtos alimentares & 8,25 & $13,54 \%$ & $35,93 \%$ \\
\hline 28 & Serviços industriais de utilidade pública & 1,01 & $1,66 \%$ & $92,72 \%$ \\
\hline 30 & Margem de comércio & 9,22 & $15,14 \%$ & $62,50 \%$ \\
\hline 31 & Margem de transporte & 2,67 & $4,39 \%$ & $76,00 \%$ \\
\hline \multirow[t]{2}{*}{33} & Seguros e serviços financeiros & 12,44 & $20,43 \%$ & $42,52 \%$ \\
\hline & TOTAL DO AGRUPAMENTO & 60,91 & $100,00 \%$ & $60,99 \%$ \\
\hline
\end{tabular}

Fonte: Dados da pesquisa.

A classificação em insumos diretos e difundidos a esse nível de análise deve ser entendida em termos qualitativos, dado que o nível de informações disponíveis impede que sejam mais precisos. Nota-se que o setor de Leite beneficiado e outros laticínios (24) não faz parte desse agrupamento, pois não é um fornecedor de insumos do setor de Leite Natural (5). A Tabela 4 também informa o grau de autonomia para cada um dos setores, o que permite avaliar o grau de autonomia total em compras desse agrupamento de setores, que é de 60,91\%. 


\section{Quarto agrupamento}

O quarto agrupamento produtivo, elaborado com base no perfil coluna do setor 24, é apresentado na Tabela 5. Como no caso anterior, distinguem-se as compras efetuadas dos setores centrais (5 e 24) das compras de outros insumos ou serviços diretos e difundidos em todo o sistema econômico. Esse agrupamento foi formado de modo a que o grau de autonomia das compras intermediárias do setor Leite Beneficiado e outros Laticínios seja de $100 \%$.

Nesse sentido, percebe-se que além dos 59,42\% e 24,08\% das compras intermediárias fornecidas pelo setor Leite Natural (5) e pelo próprio setor (24), respectivamente, existem 16,50\% de outros insumos, ou seja, as articulações intersetoriais estendem-se para outros setores da economia na forma de compras de outros insumos diretos e difundidos. A Tabela 5 também informa o grau de autonomia das compras intermediárias de cada setor dentro desse novo conjunto. O grau de autonomia global encontrado foi de 63,23\%.

Observa-se que a autonomia global das compras intermediárias do terceiro $(60,99 \%)$ e quarto $(63,23 \%)$ agrupamentos é menor que a autonomia observada no primeiro agrupamento (77,92\%), composto apenas pelos setores centrais Leite Natural e Leite Beneficiado. Isto ocorre porque foram incorporados todos os setores que fornecem insumos aos setores centrais, aumentando a necessidade de abastecimento nesses novos agrupamentos.

Tabela 5 - Análise do perfil coluna do setor 24 - Compras de insumos estaduais e grau de autonomia em compras

\begin{tabular}{llrcc}
\hline $\mathrm{N}$ & \multicolumn{1}{c}{ SETOR } & COMPRAS (R\$) & COMPRAS (\%) & AUTONOMIA \\
\hline 5 & Leite natural & 390,55 & $59,42 \%$ & $100,00 \%$ \\
13 & Papel, celulose, papelão e artefatos & 2,90 & $0,44 \%$ & $100,00 \%$ \\
15 & Demais produtos químicos & 2,78 & $0,42 \%$ & $25,25 \%$ \\
17 & Combustíveis e demais produtos do refino & 0,87 & $0,13 \%$ & $37,49 \%$ \\
24 & Leite beneficiado e outros laticínios & 158,29 & $24,08 \%$ & $100,00 \%$ \\
25 & Óleos vegetais em bruto e refinados & 0,23 & $0,03 \%$ & $30,87 \%$ \\
26 & Demais produtos alimentares & 0,44 & $0,07 \%$ & $47,39 \%$ \\
28 & Serviços industriais de utilidade pública & 6,83 & $1,04 \%$ & $93,15 \%$ \\
30 & Margem de comércio & 40,52 & $6,16 \%$ & $67,63 \%$ \\
31 & Margem de transporte & 9,31 & $1,42 \%$ & $79,37 \%$ \\
32 & Comunicações & 3,94 & $0,60 \%$ & $37,82 \%$ \\
33 & Seguros e serviços financeiros & 40,62 & $6,18 \%$ & $47,59 \%$ \\
\hline & TOTAL DO AGRUPAMENTO & 657,27 & $100,00 \%$ & $63,23 \%$ \\
\hline
\end{tabular}

Fonte: dados da pesquisa.

A Tabela 6 apresenta um resumo dos quatro agrupamentos e que foram obtidos com base na metodologia apresentada, formados pelo perfil linha e perfil coluna dos setores 5 e 24 . O perfil coluna mostra os provedores de insumos que são assimilados, e que são identificados como insumos diretos - os setores Demais Produtos Químicos (15), Óleos Vegetais em Bruto e Refinados (25) e Demais Produtos Alimentares (26); os setores restantes são classificados como insumos difundidos no sistema econômico. Devido ao elevado nível de agregação da MIP do Rio Grande do Sul não é 
possível identificar, de forma pormenorizada, os insumos utilizados em seus processos produtivos (por exemplo, açúcares e frutas utilizados na fabricação de iogurte) e sim os setores que fornecem esses insumos. Pode-se, contudo, afirmar que ficaram bem caracterizadas as ligações para frente, para trás e para os lados que se desenvolvem na economia gaúcha em torno da produção de leite natural, bem como o processo do valor de geração de valor adicionado entre os dois setores principais deste agrupamento.

Tabela 6 - Resumo dos setores dos agrupamentos produtivos identificados

\begin{tabular}{crrr}
\hline L-05 & L-24 & C-05 & C-24 \\
\hline $\mathbf{5}$ & 5 & 5 & 5 \\
24 & 24 & 13 & 13 \\
& 40 & 15 & 15 \\
& 41 & 17 & 17 \\
& 42 & 26 & 24 \\
& & 28 & 25 \\
& & 30 & 26 \\
& & 31 & 28 \\
& 33 & 30 \\
& & & 31 \\
& & & 33 \\
\hline
\end{tabular}

Fonte: Dados da pesquisa.

A Figura 3 mostra o fluxo de relacionamentos intersetoriais obtidos principalmente a partir do terceiro e quarto agrupamentos. Observa-se que o setor de Leite Natural possui 50,16\% de seus insumos classificados como difundidos pelo sistema econômico, ao passo que o setor de Leite Beneficiado utiliza apenas $16,26 \%$ de insumos difundidos, como combustíveis, comércio, transporte etc.. Quanto aos insumos diretos, o setor de Leite Natural gastou 19,13\% de suas despesas intermediárias estaduais, e o setor de Leite Beneficiado gastou apenas $0,57 \%$, revelando, ainda, uma grande dependência do setor de Leite Natural com 59,42\% de suas despesas. Este fluxo revela que as ligações para trás do setor 24 são maiores para o setor 5 do que para outros setores dos agrupamentos.

O conjunto de informações apresentadas mostra os limites do complexo lácteo do Rio Grande do Sul e suas características estruturais com seus respectivos fluxos de origem e destino de matérias-primas e produtos finais, isto é, apresenta-se um banco de dados sobre o complexo lácteo completamente integrado ao sistema econômico como um todo. 
Figura 3 - Decomposição das transações intermediárias do complexo lácteo

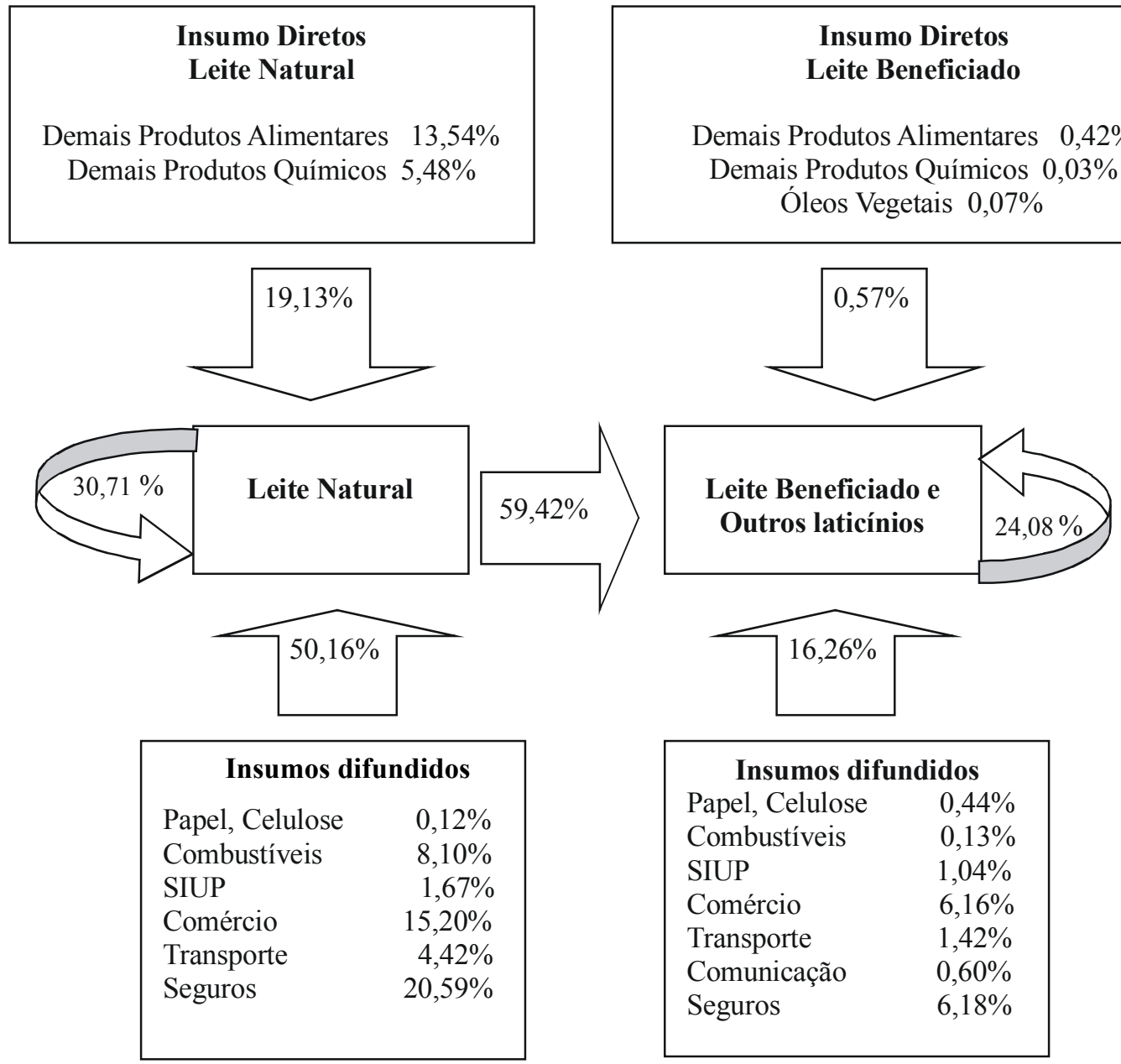

Fonte: Dados da pesquisa.

\subsection{Encadeamentos da base agropecuária (Setor 5) e da indústria láctea (Setor 24) com o con- junto da economia}

Considerando a relevância de analisar as relações intersetoriais que vão além dos limites do complexo Lácteo, torna-se necessário identificar o poder de encadeamento ou o efeito dinamizador do setor Leite Natural (setor 5) e do setor Leite Beneficiado e outros laticínios (setor 24) que formam o núcleo do complexo Lácteo sobre o resto do sistema econômico.

Os efeitos dinamizadores desses setores podem ser avaliados por meio do multiplicador tipo 1 (modelo aberto de Leontief) e dos índices de encadeamentos para trás e para frente apresentados na Tabela 7. A consideração do ranking dos multiplicadores e encadeamentos incide, de maneira decisiva, na avaliação dos potenciais efeitos dinamizadores de uma determinada atividade, uma vez que salientam diferenças relativas substanciais. 
Tabela 7 - Multiplicador tipo I e encadeamento total, para trás e para frente (matriz produtoproduto de dimensão $43 \times 43$ )

\begin{tabular}{|c|c|c|c|c|c|c|c|c|c|}
\hline \multirow[b]{2}{*}{$\mathrm{N}$} & \multirow[b]{2}{*}{ SETORES } & \multirow[b]{2}{*}{$\begin{array}{c}\text { Mutiplicador } \\
\text { tipo I }\end{array}$} & \multirow[b]{2}{*}{ Rank } & \multicolumn{6}{|c|}{ ENCADEAMENTOS } \\
\hline & & & & TRÁS & Rank & FRENTE & Rank & TOTAL & Rank \\
\hline 1 & Arroz em casca & 1,18739 & 39 & 0,85651 & 39 & 1,05247 & 13 & 1,90899 & 26 \\
\hline 2 & Soja em grão & 1,20792 & 37 & 0,87132 & 37 & 1,26350 & 8 & 2,13482 & 10 \\
\hline 3 & Milho em grão & 1,22272 & 35 & 0,88200 & 35 & 1,08952 & 11 & 1,97152 & 21 \\
\hline 4 & Bovinos e suínos & 1,39520 & 21 & 1,00641 & 21 & 1,17230 & 9 & 2,17872 & 9 \\
\hline \multirow[t]{3}{*}{5} & Leite natural & 1,19232 & 38 & 0,86007 & 38 & 0,99918 & 15 & 1,85925 & 27 \\
\hline & . & . & . & . & · & . & . & . & . \\
\hline & . & . & . & . & . & . & . & . & . \\
\hline \multirow[t]{4}{*}{24} & Leite beneficiado e outros laticínios & 1,65682 & 8 & 1,19513 & 8 & 0,81876 & 26 & 2,01389 & 16 \\
\hline & . & & . & . & . & . & . & . & - \\
\hline & & & . & . & · & . & . & . & . \\
\hline & . & & . & . & . & . & . & . & . \\
\hline 43 & Serviços privados não-mercantis & 1,03474 & 43 & 0,74640 & 43 & 0,72134 & 43 & 1,46774 & 43 \\
\hline
\end{tabular}

Fonte: Dados da pesquisa.

Ao se analisar os multiplicadores e os efeitos de encadeamento sobre o produto da economia fica evidente que as atividades centrais do complexo Lácteo (setor 5 e 24) têm importante efeito dinamizador na economia gaúcha. O setor 5, Leite Natural, ocupa, dentre as atividades que mais contribuem para a renda da economia, o $38^{\circ}$ lugar. Contudo, se fossem considerados os encadeamentos totais do produto, o setor ocuparia o $27^{\circ}$ lugar dentre as atividades de maior efeito dinamizador; dentre os encadeamentos para trás, o setor ocupa o $38^{\circ}$ lugar, e dentre os encadeamentos para frente, o $15^{\circ}$ lugar. As ligações intersetoriais são importantes em ambos os sentidos, sendo que, em termos relativos, são mais importantes os encadeamentos para frente, o que já era esperado por se tratar de um setor típico provedor de matéria-prima.

No caso do setor 24, Leite Beneficiado e outros Laticínios, sua contribuição na geração de renda para a economia se localiza no oitavo lugar. Se forem considerados os encadeamentos do setor, verifica-se que se trata de um setor receptor, com um importante efeito dinamizador para trás como demandante de insumos, ocupando também o oitavo lugar dentro da economia estadual. Entretanto, os efeitos para frente são mais reduzidos (26ํㅣㅁ lugar), uma vez que nesse setor ocorre o último processamento da matéria-prima antes de ser direcionado para o consumo final.

Complementando a análise de multiplicadores e efeitos de encadeamento apresentados, e obtidos por meio de uma matriz insumo-produto elaborada com base na tecnologia produto-produto, as Tabelas 8 e 9 apresentam uma série de multiplicadores e índices de encadeamento, elaborados pela FEE, com base numa matriz compilada sob a tecnologia setor-setor. 
Tabela 8 - Encadeamento total, para trás e para frente, RS - 1998 (matriz setor-setor de dimensão 26 × 26)

\begin{tabular}{|c|c|c|c|c|c|c|c|c|c|}
\hline \multirow{2}{*}{$\begin{array}{l}\text { Código } \\
\text { da Ativi- } \\
\text { dade }\end{array}$} & \multirow[t]{2}{*}{ Descrição das atividades } & \multicolumn{3}{|c|}{ Índices de ligação para frente } & \multirow[t]{2}{*}{ Rank } & \multicolumn{3}{|c|}{ Índices de ligação para trás } & \multirow[t]{2}{*}{ Rant } \\
\hline & & $\begin{array}{l}\text { Modelo } \\
\text { Aberto }\end{array}$ & $\begin{array}{l}\text { Efeito- } \\
\text { Renda }\end{array}$ & Total & & $\begin{array}{c}\text { Modelo } \\
\text { Aberto }\end{array}$ & $\begin{array}{l}\text { Efeito- } \\
\text { Renda }\end{array}$ & Total & \\
\hline 01 & Agropecuária & 3,85 & 1,70 & 5,55 & 01 & 1,28 & 0,73 & 2,01 & 17 \\
\hline 02 & Metalurgia & 1,32 & 0,02 & 1,35 & 16 & 1,20 & 0,61 & 1,81 & 23 \\
\hline . & . & . & . & . & . & . & . & . & . \\
\hline . & . & . & . & . & . & . & . & . & . \\
\hline . & . & . & . & . & . & . & . & . & . \\
\hline 14 & Leite e laticínios & 1,13 & 0,35 & 1,49 & 13 & 1,66 & 0,73 & 2,40 & 03 \\
\hline . & . & . & . & . & . & . & . & . & . \\
\hline . & . & . & . & . & . & . & . & . & . \\
\hline$\cdot$ & . & . & . & . & . & . & . & . & . \\
\hline 26 & Administração pública & 1,00 & 0,00 & 1,00 & 26 & 1,20 & 0,81 & 2,01 & 16 \\
\hline
\end{tabular}

Fonte: FEE, Núcleo de Contabilidade Social.

Tabela 9 - Multiplicadores de impacto leite natural, beneficiado e outros laticínios, RS - 1998 (matriz de dimensão $26 \times 26$ )

\begin{tabular}{lrrrrc}
\hline Multiplicador & Direto & Indireto & Efeito-Renda & Total & Rank \\
\hline Multiplicador de Valor Adicionado & 0,44 & 0,41 & 0,51 & 1,36 & 08 \\
Multiplicador de Emprego & 8 & 60 & 42 & 109 & 09 \\
Multiplicador de Rendimento & 0,05 & 0,15 & 0,23 & 0,42 & 17 \\
Multiplicador de ICMS & 0,04 & 0,02 & 0,03 & 0,09 & 17 \\
Multiplicador de IPI/ISS e outros impostos & 0,00 & 0,00 & 0,01 & 0,01 & 25 \\
Multiplicador do imposto de Importação & 0,00 & 0,00 & 0,00 & 0,00 & 12 \\
\hline
\end{tabular}

Fonte: FEE, Núcleo de Contabilidade Social.

A Tabela 8 mostra os encadeamentos para trás e para frente, considerando os setores de Leite e Laticínios conjuntamente. Verifica-se que os setores Leite e Laticínios, de forma agregada, constituem-se em setores-chaves para o processo de crescimento do Estado, uma vez que no ranking estadual as ligações para frente ocupam o 13ํํำ lugar e as ligações para trás o terceiro lugar dentre os 26 setores econômicos. Em decorrência disso, quando analisados os multiplicadores da Tabela 9 fica evidente que o complexo lácteo é um importante gerador de valor adicionado ( $8^{\circ}$ lugar), de emprego ( $9^{\circ}$ lugar) e de rendimentos (17ํㅡㄹ lugar). O complexo lácteo também se constitui em importante fonte de receitas fiscais para o Estado, uma vez que os multiplicadores de ICMS e de importação ocupam a $17^{\underline{a}}$ e a $12^{\underline{a}}$ posições, respectivamente, no ranking estadual.

Em síntese, o conjunto de informações, além de mostrar os limites do complexo lácteo gaúcho, mostra também que se trata de um conjunto de atividades com fortes inter-relações com o total da economia estadual. 


\section{CONCLUSÕES}

O artigo teve como objetivo identificar os agrupamentos e as atividades fortemente inter-relacionadas com o complexo lácteo, com o propósito de avaliar as articulações que se estendem para outros setores provedores de insumos - bens de capital, serviços - e de outras indústrias agroalimentares que utilizam a produção de leite natural e a produção da indústria láctea como insumos.

Como resultado, verificou-se que a produção de leite natural é quase que integralmente destinada para a demanda intermediária, em particular para a indústria gaúcha de Leite Beneficiado e outros Laticínios. A indústria de Leite Beneficiado, por sua vez, é fundamentalmente produtora de bens finais, apresentando um mínimo de interligações com outras indústrias alimentícias. Trata-se, portanto, de um agrupamento produtivo com um nível elevado de autonomia no suprimento de insumos, ou seja, um agrupamento em processo de expansão.

Verificou-se também que a indústria de Leite Beneficiado e outros Laticínios, além de abastecer o mercado estadual, é um exportador líquido para outros estados brasileiros, o que deixa em evidência as vantagens comparativas e competitivas do Rio Grande do Sul nesse mercado.

Os fluxos de relacionamentos intersetoriais obtidos a partir do terceiro e quarto agrupamentos revelam que metade dos insumos utilizados pelo setor de Leite Natural é classificado como insumos difundidos (combustíveis, comércio, transporte etc.) pelo sistema econômico, ao passo que o setor de Leite Beneficiado utiliza apenas um sexto de seus gastos com os insumos difundidos. Esse fato mostra que a produção de matéria-prima do complexo lácteo está bastante interligada com o resto da economia. Por sua vez, o fluxo de insumos diretos do setor de Leite Natural situa-se ao redor de um quinto de suas despesas intermediárias estaduais, e o setor de Leite Beneficiado gasta menos de um por cento, revelando uma grande dependência do setor de Leite Natural (setor central), com despesas próximas a $60 \%$.

Por meio da relação Valor Adicionado/Valor Bruto da Produção fica evidente que, em termos relativos, o setor Leite Natural adiciona mais valor que a indústria de Leite Beneficiado e outros Laticínios. Para explicar esse aparente paradoxo deve-se levar em consideração o total de ativos (estoques de capitais) utilizados pelos respectivos setores produtivos. O que se precisa saber é qual a renda (fluxo) gerada por unidade de investimento (estoque) no setor de produção rural (Leite Natural) relativamente à renda do setor a jusante (Indústria Láctea). No entanto, as informações sobre os estoques de capital não estão disponíveis para o Rio grande do Sul. Assim, há que se considerar que o setor de Leite Natural, embora obtenha uma margem de contribuição elevada, tem também elevados custos de oportunidade do investimento em razão dos altos valores dos ativos utilizados em terra, maquinário, animais e outras condições de produção. Além desses fatores de longo prazo, é verificado na literatura, numa análise de curto prazo, que existem custos variáveis baixos na produção leiteira nacional, mas que, em decorrência da pequena escala de produção das propriedades, o produtor obtém baixos lucros totais.

Por outro lado, quando avaliados os multiplicadores e os efeitos de encadeamentos, verificouse que o complexo lácteo tem fortes ligações intersetoriais que dinamizam a economia gaúcha como um todo, o que poderá servir de base para a elaboração de políticas públicas como um alicerce para o crescimento econômico.

A principal contribuição desta pesquisa é fornecer um conjunto de informações do complexo lácteo fortemente integradas ao sistema econômico como um todo, que permite visualizar o fluxo de insumos e bens finais por origem e destino, bem como a dimensão econômica e o alcance que têm o complexo lácteo gaúcho. Neste sentido, o trabalho delimitou, com bastante clareza, as liga- 
ções que o complexo apresenta, fato que permanentemente é uma dificuldade nos diversos estudos dos sistemas agroindustriais.

Vale salientar que o estudo futuro de comparações entre cadeias produtivas regionais é altamente importante porque a concorrência se dá entre cadeias produtivas e não entre produtos industrializados. Os complexos produtivos que conseguirem maior harmonia entre seus componentes levarão vantagens na competição. As trocas de informações entre as cadeias produtivas nacionais poderão fortalecer a competição dos produtores nacionais ante outros países do mundo. O desenvolvimento econômico acelerado em uma região rica em recursos naturais dependerá da rapidez com que esta aprenda a industrializar e a processar seus recursos naturais, assim como a desenvolver as atividades provedoras de insumos, serviços de engenharia e equipamentos para essas atividades.

\section{BIBLIOGRAFIA}

Araújo, N. B. et alii. Complexo agroindustrial. O agribusiness brasileiro. São Paulo, dez. 1990. 228 p.

Davis, J.; Goldberg, R. A concept of agribusiness. Boston: Harvard University, 1957.

FEE. Matriz de insumo-produto do Rio Grande do Sul. CD-Rom, 1998.

. Tabelas de multiplicadores de impacto revisadas. Disponível em: http://www.fee.rs.gov.br/sitefee/download/matriz/tb_indicadores.zip. (capturadas em 26 de março de 2004).

Finamore, E. B. O crescimento setorial da economia brasileira no período 1985/96: uma análise de insumo-produto. 2001. 166p. Tese (doutorado). Universidade Federal de Viçosa. Viçosa - MG.

Furtuoso, M. O produto interno bruto do complexo agroindustrial brasileiro. 1988. Tese (Doutorado), ESALQ/USP.

Gomes, S. T. Economia da produção do leite. Belo Horizonte, 2000.

Guilhoto, J. J. M.; Furtuoso, M. C. O.; Barros, G. S. C. O agronegócio na economia brasileira, 1994 a 1999. São Paulo: Confederação Nacional da Agricultura, 2000,142p.

Hirschman, 1956

Lauschner, R. Agribusiness, cooperativa e produtor rural. São Leopoldo: Unisinos, 1993, 296p.

Leontief, W. The structure of the American economy in 1951. New York: Ed. Ampl., Oxford University Press, 1951.

Montoya, M. A.; Finamore, E. B. Evolução do PIB do agronegócio brasileiro de 1959 a 1995: uma estimativa na ótica do valor adicionado. Revista Teoria e Evidência Econômica (UPF), Passo Fundo RS: UPF editora, v 9, n. 16, p. 9-24, maio de 2001.

Montoya, M. A.; Guilhoto, J. J. M. O agronegócio brasileiro entre 1959 e 1995: dimensão econômica, mudança estrutural e tendências. In: Montoya, M. A.; Parré, J. L. (eds.), O agronegócio brasileiro no final do século XX. Passo Fundo - RS: Ediupf, 2000, p. 3-32.

Montoya, M. A. et alii. O agronegócio nos estados da região sul no período de 1985 a 1995. Revista Economia Aplicada (USP), v. 5, n. 1, p. 99-127, jan./mar. 2001.

Ramos, J. Uma estratégia de desarrollo a partir de complejos productivos em torno a los recursos naturales. Revista de la Cepal, v. 66. p. 105-125, 1998.

Rasmussen, 1958

Vaillant, M. El complexo productivo lácteo en Uruguay. In: Apertura economica y (des)encadeamentos productivos. Cepal, 1999, p. 263-314. 


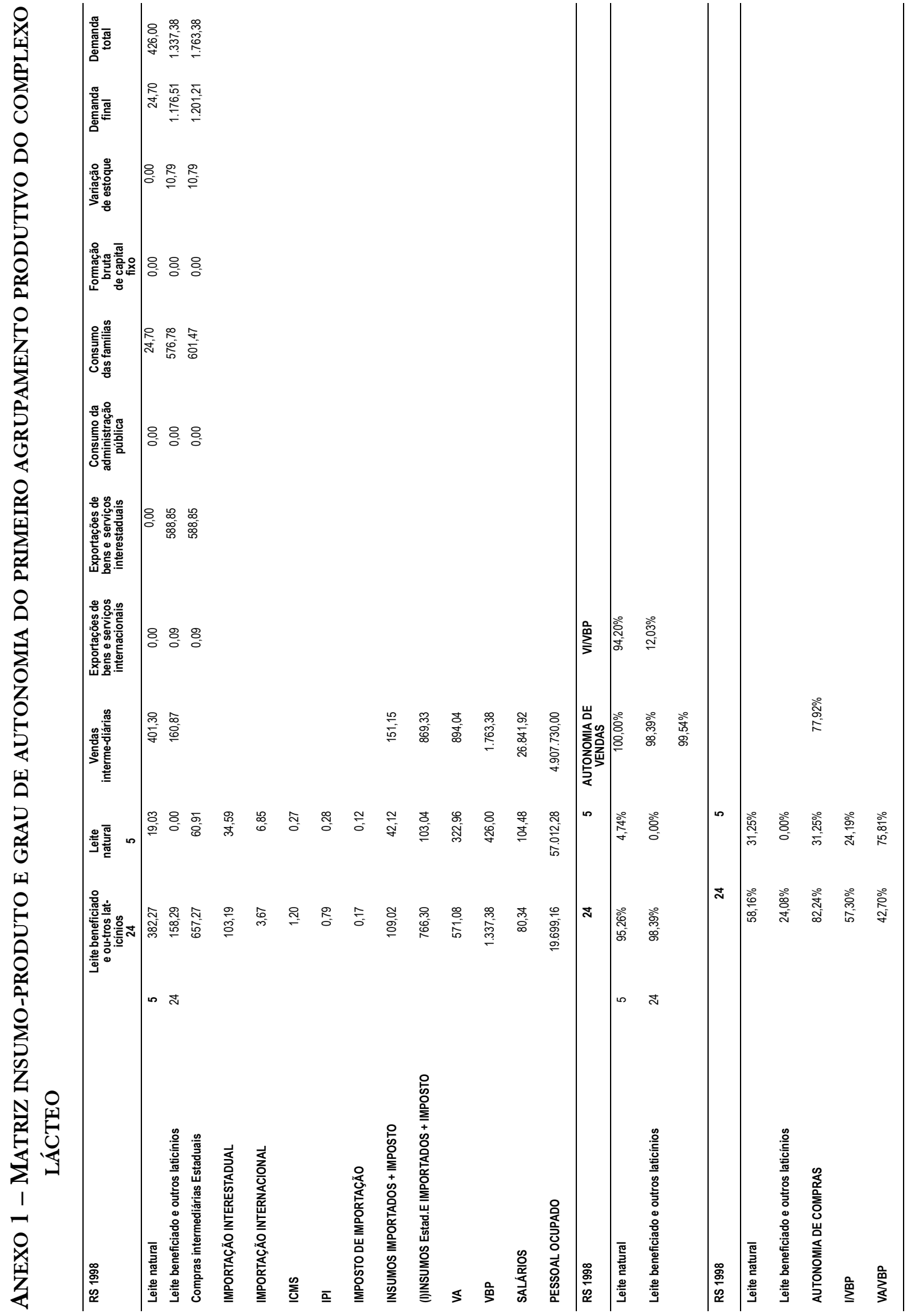




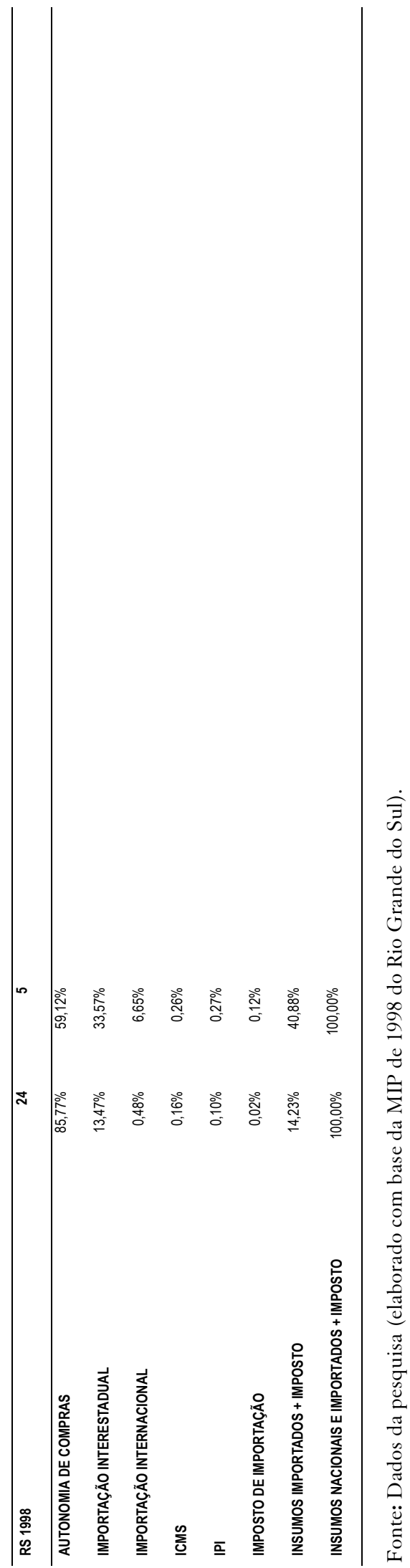

Econ. Aplic., 9(4): 663-682, out-dez 2005 